\title{
Development of a standardized scoring method for the Graphic Sequence Test suitable for use in psychiatric populations
} Konstantinos Fountoulakis*1,2, Panagiotis Panagiotidis ${ }^{1}$, Melina Siamouli ${ }^{1}$, Stamatia Magiria ${ }^{1}$, Stavroula Sokolaki ${ }^{1}$, Sotiris Kantartzis ${ }^{1}$, Klairi Rova ${ }^{1}$, Natalia Papastergiou ${ }^{1}$, George Shoretstanitis ${ }^{1}$, Timucin Oral ${ }^{1}$, Theoharis Mavridis ${ }^{1}$, Apostolos Iacovides ${ }^{1}$ and George Kaprinis ${ }^{1}$

Address: ${ }^{13 r d}$ Department of Psychiatry, Aristotle University of Thessaloniki, Greece and 25 th Inpatient Department of Psychiatry and Outpatient Unit of Mood Disorders, Bakirkфy State Teaching and Research Hospital for Neuropsychiatry, Istanbul, Turkey

* Corresponding author

\author{
from International Society on Brain and Behaviour: 3rd International Congress on Brain and Behaviour \\ Thessaloniki, Greece. 28 November - 2 December 2007 \\ Published: 17 April 2008 \\ Annals of General Psychiatry 2008, 7(Suppl I):S289 doi:I0.II86/I744-859X-7-SI-S289
}

This abstract is available from: http://www.annals-general-psychiatry.com/content/7/SI/S289

(C) 2008 Fountoulakis et al.; licensee BioMed Central Ltd.

\section{Background}

Although the graphic version of the Alternating Sequences Test which was introduced by Luria exists for years little has been done to standardize it. The aim of the current study was to develop a novel and detailed standardized method of administration and scoring.

\section{Materials and methods}

The study sample included 93 normal control subjects ( 53 females and 40 males) aged $35.87 \pm 12.62$ and 127 patients suffering from schizophrenia (54 females and 73 males) aged $34.07 \pm 9.83$. The psychometric assessment included the PANSS the YMRS, and the MADRS.

\section{Results}

A scoring method was developed and was based on the frequencies of responses of healthy controls. Chronbach's alpha and test-retest and inter-ratter reliability were very good. Two indices and six subscales of the Standardized Graphic Sequence Test (SGST) were eventually developed.

\section{Conclusions}

The SGST seems to be a reliable, valid and sensitive to change instrument based on Luria's graphic sequence test. The great advantage of this instrument is the fact that it is paper and pencil, easily administered and little time con- suming. Further research is necessary to test its usefulness as a neuropsychological test. 